\title{
The true cost of the economic crisis on psychological well-being: a review
}

This article was published in the following Dove Press journal:

Psychology Research and Behavior Management

9 January 2015

Number of times this article has been viewed

\section{Guido Van Hal}

Medical Sociology and Health Policy, University of Antwerp, Antwerp, Belgium

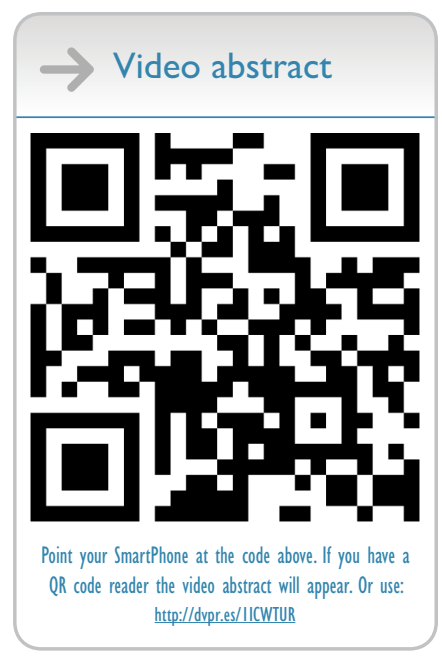

Correspondence: Guido Van Hal University of Antwerp, Universiteitsplein I, 2610 Antwerp, Belgium

Tel +32 32652520

Fax +32 32652875

Email guido.vanhal@uantwerp.be
Abstract: The recent economic crisis has led to many negative consequences, not the least having to do with the mental health and well-being of the populations involved. Although some researchers say it is still too early to speak about a relationship between the economic crisis and a rise in mental health problems resulting in suicides, there is solid evidence for the existence of such a relationship. However, several moderating or mediating mechanisms can also play a role. The main reactions of most policy makers to the economic crisis are (severe) austerity measures. These measures seem to have, however, a detrimental effect on the mental health of the population: Just when people have the highest need for mental help, cost-cutting measures in the health care sector lead to a (substantial) drop in the supply of services for the prevention, early detection, and cure of mental health problems. Policy makers should support moderating mechanisms such as financial and psychological coping and acculturation and the role of primary health care workers in the early detection of suicidal thoughts, suicide attempts, and suicide in times of economic recession. Several examples show that the countries best off regarding the mental health of their populations during the economic crisis are those countries with the strongest social safety net. Therefore, instead of cutting back on health care and social welfare measures, policy makers should in the future invest even more in social protection measures during economic crises.

Keywords: economic recession, mental health, suicide, social protection, austerity, review

\section{Introduction}

Recently, many scientific publications have focused on the severe economic crisis in Greece and its negative consequences on the population's health. ${ }^{1-6}$ This theme has become and still is highly topical. More specifically, the economic crisis and the subsequent austerity measures seem to have thoroughly influenced the psychological well-being of the nation. One mechanism at stake here is job loss and unemployment: It is incontrovertible that losing one's job and being unemployed can have a negative effect on mental health. Several studies have shown that unemployment is associated with suicidal thoughts. ${ }^{7-13}$

As a result of the worst financial economic crisis seen in decades, which started in the summer of 2008, there were a large number of corporate restructures and bankruptcies, leading to a significant level of labor force dismissals. Although Greece was hit by the earliest signs and possibly experienced the most severe effects of this phenomenon, it soon became apparent that a majority of countries worldwide fell victim. After a while, it became clear that the negative consequences of the economic crisis on mental health were not limited to the countries most hit by the crisis, such as, 
for instance, Spain and Portugal, in addition to Greece, but also that a lot of other countries saw an increase in mental health problems and suicides during the Great Recession. However, some scientists still doubt the relationship between the consequences of the economic crisis and austerity measures on the mental health of the population. They say that the concept of economic crisis-related increased suicidality is a premature overinterpretation. ${ }^{14-16}$ This has led to a lively discussion in scientific journals. ${ }^{17-19}$

As in any good scientific tradition, it is therefore very important to assess, in an evidence-based way, the precise effect, if any, this crisis has had on people's health. Only then will it be possible to inform policy makers about which measures should be taken to safeguard public health in times of economic hardship and austerity.

In this review, we more precisely look at scientific research published on the effect on mental health, suicidal thoughts, suicide attempts, and completed suicides of the economic crisis. Furthermore, we look at the role job loss and unemployment play in this story.

However, it does not seem that easy to assess the effect of the economic crisis on (mental) health. Contrary to economic data, (recent) health data are not always available; as Martin McKee, an expert on this domain says: "In times of financial downturn, the health of the economy is monitored by the second, yet the available data on the health of the population is usually a couple of years out of date."20

Nevertheless, there is growing scientific evidence of a negative effect on (mental) health resulting from the recent economic crisis, as expressed by the interest of the World Health Organization (WHO), European Region, in this topic. On April 17 and 18, 2013, the WHO held a conference on health systems and the economic crisis. On that occasion, WHO Regional Director for Europe Zsuzsanna Jakab said,

"That is WHO's call to all governments in our region: if you have to cut, cut wisely, not broadly, and protect the vulnerable to ensure universal health coverage. This is at the heart of the WHO European policy, Health 2020.

Evidence shows that inappropriate cuts in the health sector can worsen the situation. At the same time, the health sector should do all it can to minimize wasteful spending and ensure that the resources available are focused on services of proven value." ${ }^{21}$

As already addressed, it is not that easy to assess an evidence-based relationship between the recent economic downturn and health. Whether someone's health is good or bad is dependent on many factors, and to sort out the precise contribution attributable to the economic crisis is not self-evident. Moreover, for several reasons, which will be elaborated further, all-cause mortality rates do not show an increase during economic crises. ${ }^{22}$ On the contrary, Baumbach et al found in their study in eight European countries that the trend of overall mortality continued to decline after crisis onset in $2008 .^{23}$

However, we have something to hold on to. First, it is possible to learn from previous economic crises. Moreover, we can narrow the focus to specific health consequences of the economic crisis. When, for instance, the focus is narrowed to suicide mortality, the pattern of associations becomes more clear-cut. $^{22}$ Suicide risk should perhaps be seen as the tip of a psychiatric iceberg: ${ }^{22}$ A rise in the number of suicides is only a small part of the emotional distress caused by the economic downturn. ${ }^{24}$ Nonfatal suicide attempts could be 40 times more common than completed suicides, ${ }^{25}$ and for every suicide attempt made, about 10 more people experience suicidal thoughts. ${ }^{26}$

\section{Methods used to measure changes in psychological distress during the recession}

When trying to assess the effect of the economic crisis on (mental) health, one is confronted with several methodological problems. The first is the question of how to define the financial crisis, because this determines when the economic crisis started. ${ }^{19}$ Although one can discuss the definition, most authors agree that the start of the economic crisis was in the summer of 2008 .

A second methodological problem is how to measure (mental) health. We found many different ways to measure mental health, among which are surveys on mental disorders/ suicidal thoughts in a primary care setting ${ }^{27,28}$ or secondary data analysis (health interview surveys). Rihmer et al looked at annual antidepressant consumption, which can be seen as a possible proxy for the availability of psychiatric services and the treatment of depression, which is the most powerful predictor of suicide at the individual level. ${ }^{29}$

When looking at suicide as an adverse effect of the economic crisis, an additional problem of lack of data or of misclassification can arise.

To link the occurrence of the economic crisis to its possible adverse health outcomes, mostly correlational ecological studies were performed. This means observational analyses based on aggregate data. Most authors looked at the difference between the situation before and after the start of the economic crisis. Regarding suicides, the aim was 
to find excess suicides attributable to the economic crisis. This could be done by using time-trend regression models to assess excess suicides occurring during the economic crisis (ie, deaths over and above the level that would be expected if historical trends continued). ${ }^{30}$

As mentioned earlier, however, some studies also used data on an individual level. In that regard, there was, for instance, a study that did a follow-up survey in migrants in Spain to measure their mental health in 2008 and 2011 . $^{31}$

\section{Evidence for effects on mental health Suicide (deaths, attempts, ideation)}

In Greece, where the recent economic crisis in Western Europe started, a 40\% rise in suicides in the first half of 2011 compared with the same period in 2010 was observed..$^{32}$ The main reasons of suicidal thoughts, as reported by the national suicide helpline, were financial difficulties in $2010^{33}$ and the inability to repay high levels of personal debt, which might be a key factor in the increase in suicides. ${ }^{34}$

The financial crisis in Spain was associated with an 8.0\% relative increase in the suicide rate above the underlying trend, ${ }^{35}$ and in Italy, excess suicides and attempted suicides attributable to the Great Recession also were reported. ${ }^{36}$

Stuckler et al found that in 26 European countries, suicide rates increased; the exception was Austria. In each of the other countries, the increase was at least 5\%. ${ }^{37}$ In Belgium, a statistically significant relationship between losing one's employment in the past year and having suicidal thoughts during the economic crisis was found. ${ }^{28}$

In their study in eight European countries (Germany, Finland, Portugal, Slovenia, Poland, Czech Republic, Slovakia, and Bulgaria), Baumbach et al found that in particular, mental health is affected by the economic crisis, as the increase in suicide mortality in most of these countries showed. ${ }^{23}$

Further, during the recessionary period after 2007, there were an estimated 4,750 excess suicide deaths in the United States, of which about 1,330 were caused by rising unemployment. ${ }^{30}$

Chang et al found an estimated number of 4,884 excess suicides in 2009 compared with the number expected based on previous trends (2000-2007) in 54 countries. ${ }^{24}$ However, in Europe, excess suicides mainly occurred in men aged 15-24 years, whereas in the Americas, men aged 45-64 years showed the largest increase. The increase was particularly seen in countries with low levels of unemployment before the crisis, in men, and in countries with higher levels of job loss. When looking at Asia, Ryall mentioned an increase in suicides during the 2008 economic crisis in Japan. ${ }^{38}$ In a publication on the 1997-1998 crisis in East/Southeast Asia, Chang et al found a marked increase in suicide rates in Japan (39\%), Hong Kong (44\%), and South Korea (45\%) corresponding to a total of more than 10,000 additional suicide deaths. Increases were smaller in Taiwan and Singapore, where the economic effect on populations was less severe. ${ }^{39}$

Countries most hit by the economic crisis, such as Greece and Ireland, had greater rises in suicides (17\% and $13 \%$, respectively) than other countries. ${ }^{37}$ This could be an indication of a kind of dose-response effect, which seems to be underpinned by the fact that every $1 \%$ increase in unemployment was associated with a $0.79 \%$ rise in suicides at ages younger than 65 years in 26 European Union countries between 1970 and $2007 .{ }^{40}$ A similar result was found in Italy, where every annual $1 \%$ increase in unemployment corresponded to an increase of 0.074 per 100,000 deaths resulting from mental and behavioral disorders, ${ }^{41}$ as well as in the United States, where a one percentage point rise in unemployment was associated with a rise in the suicide rate of $0.99 \%$, which is, compared with Europe, closer to the association estimated when there were no labor market protections $(1.06 \%){ }^{30}$ These figures are in line with what was already indicated by previous studies; namely, unemployed people have a two to three times increased risk for suicide. ${ }^{42}$

\section{Prevalence of mental disorders and other indices of poor mental health}

Economou et al found more than a doubling in the prevalence rate of major depression between 2008 and 2011 in Greece..$^{43}$ Focusing on mental disorders rather than suicide can be interesting and help avoid some pitfalls, as suicide is often a delayed consequence of an underlying mental health disorder rather than the result of an immediate response to stressful life events. ${ }^{44}$

Looking at Spain, an increase in the prevalence of poor mental health among men and a slight decrease among women between 2006-2007 and 2011-2012 was observed. Among men, this increase is attributed to employment status. The data suggest that the improvement in mental health is concentrated among employed women, who may experience additional recognition and greater self-esteem in a new breadwinner role. ${ }^{45}$

Still talking about Spain, there seemed to be substantial increases in the proportion of patients with mood disorder, anxiety, somatoform, and alcohol-related disorders according 
to the 2010 data compared with the 2006 data, which were gathered before the crisis. ${ }^{27,44}$

Gili et al reported a substantially increased risk for major depression associated with mortgage repayment and evictions in Spain. ${ }^{27}$

In addition, Hungarian data support the theory that the current global recession has deleterious effects on society's mental health. ${ }^{29}$

In another review, an increase in the prevalence of depression and anxiety related to the economic crisis also was found. ${ }^{22}$

\section{Prevalence of substance use}

When we look outside Europe, Cooper, in his overview of economic recession and mental health, mentions an increase in drug use in the United States and notes that the estimated total of unemployed drug users rose from 1.3 to 2.5 million within the space of 2 years. ${ }^{22}$

For Russia, several studies reported that mortality resulting from alcohol-related diseases, namely, unintentional alcohol poisoning, liver diseases, and especially cirrhosis, was increased during economic crisis. ${ }^{46-50}$ In addition, Cooper reports an increase in alcohol-related disorders related to the economic crisis. ${ }^{22}$

In contrast, in some countries, a reduction in the use of alcohol was observed. There were marked reductions in alcohol consumption, for instance, in Greece, ${ }^{51}$ and drinkdriving was also decreased. ${ }^{52}$ The reduction in alcohol consumption, however, might be restricted to those least hit by the economic crisis, as was found by Harhay et al in England: "England's recession was associated with less hazardous drinking among the population overall, but with rises in binge drinking among a smaller high-risk group of unemployed drinkers. ${ }^{93}$ This is in line with the findings of Stuckler et al, who found a European Union-wide mean of 3,500 potential alcohol-related excess deaths associated with an increase in unemployment. ${ }^{40}$

\section{Use of services}

According to a review, Cooper also reports an increase in mental health service use related to the economic crisis. ${ }^{22}$

In Greece, despite their feeling it was necessary, there was a rise of $15 \%$ of people not going to the doctor and $14 \%$ in people not going to the dentist. ${ }^{1}$ Because general practitioner visits are free of charge and outpatient clinics of hospitals can be attended for $€ 0-5$, it seems these unmet medical needs mainly can be attributed to supply-side problems, such as $40 \%$ cuts in hospital budgets, ${ }^{54}$ understaffing, reported occasional shortages of medical supplies, and bribes given to medical staff to jump queues in overstretched hospitals, ${ }^{55}$ all indicating the powerful effect of austerity measures.

Still in Greece, there was a rise in admissions to public hospitals of $24 \%$ in 2010 compared with $2009,{ }^{56}$ whereas a $25 \%-30 \%$ decline in admissions to private hospitals was reported. ${ }^{57}$ Street clinics run by nongovernmental organizations, until a few years ago, mainly catered to immigrants, but it is estimated that the proportion of Greeks seeking medical attention from their street clinics rose from $3 \%-4 \%$ before the crisis to about $30 \%$ afterward. ${ }^{58}$

\section{Other effects of the economic crisis}

There also was a significant rise in the prevalence of people in Greece reporting that their health in general was "bad" or "very bad."

In addition, HIV infections increased in Greece in late 2010, with half of the increases attributable to infections among intravenous drug users. ${ }^{59}$ This is also produced by scaled-back preventive programs, for example, needle exchange and early treatment services ${ }^{21}$ and by an increase in the number of heroin users (by 20\% in 2009) ) $^{52}$ and an increase in prostitution. ${ }^{60}$ Violence, homicide, and theft rates nearly doubled between 2007 and 2009. ${ }^{61-63}$

Abbott and Wallace ${ }^{64}$ also addressed the consequences on health of the economic crisis in post-Soviet Russia. They note that the economic transition from planned market economies was accompanied by economic crisis exemplified in declining gross domestic product, hyperinflation, and cuts in state welfare spending, resulting in several negative effects; including, among others, a lack of economic security and a decline in well-being. ${ }^{64}$ Abbott and Wallace also showed, using qualitative and quantitative data, that a majority of the population had a poor quality of life, with the one remaining source of security for many being the support they got from close family and friends. ${ }^{64}$

In general, a decrease in traffic accidents is also observed. ${ }^{22}$ The decline in transport accident mortality also might be attributed to less economic activity. ${ }^{23}$

The fall in traffic accidents is one of the reasons that all-cause mortality rates did not show an increase during the economic crisis.

Thomas et al found that some positive consequences of the economic crisis in Ireland could be more productivity and improved efficiency ${ }^{65}$ However, they immediately put this into perspective: "Were the only message more productivity and improved efficiency - then a mild and brief austerity 
programme might be the boot camp needed for a lagging health system. Nevertheless, the prolongation of austerity, coupled with other less appealing adjustment policies, has yielded increased rationing." ${ }^{65}$

\section{Relationships among mental health and unemployment, debt, and poverty}

Because of the economic crisis, employment was threatened for a lot of people. Kentikelenis et al stated, about the Great Recession in Greece, that adult unemployment had risen from $6.6 \%$ in May 2008 to $16.6 \%$ in May 2011. ${ }^{1}$ Stuckler et al found that in 26 European countries, job loss increased to about 35\% above the 2007 level after 2009 in both old and new European Union Member States. ${ }^{37}$

Uutela reported, based on a review, that in European Union countries, rising unemployment was associated with significant short-term increases in premature deaths from intentional violence, including suicides. ${ }^{66}$

The abovementioned observation that higher levels of job loss go together with a higher increase in suicides has led to some discussion. Fountoulakis et al were throwing doubt on Reeves' suggestion ${ }^{30}$ that the suicide rate in the United States has increased since 2007 in direct correlation to the increase in unemployment caused by economic recession. ${ }^{67}$ Fountoulakis' point is that in this case, the cause-and-effect interpretation remains problematic. However, Perlman and Bobak already brought forward the idea that the rapidity of the health consequences of financial crises can be explained by the adverse effects of anticipating job loss and job insecurity. ${ }^{68}$ Moreover, Reeves et al clearly stated that unemployment is only one of the factors that increase suicide in a recession, with others, such as the rise in personal debt and mortgage foreclosures (which occur before rises in unemployment), also affecting mental health. ${ }^{69}$

\section{Vulnerable groups}

In general, people facing financial difficulties are at greater risk for mental disorders. In Britain, people mired in debt have two to three times the frequency of depression or psychosis, double that of alcohol dependence, and four times that of drug dependence compared with the general population. ${ }^{70}$

It is obvious that this association is reinforced during times of economic hardship and that this subgroup in the population is hit harder by the economic crisis than others.

The national suicide helpline in Greece, for instance, reported that $25 \%$ of callers faced financial difficulties in $2010,{ }^{33}$ and reports in the media indicate that the inability to repay high levels of personal debt might be a key factor in the increase in suicides. ${ }^{34}$

This seems to be a worldwide phenomenon. In developing countries, especially the "extreme poverty" class of those subsisting on US\$1.25 daily or less, are badly hit by the economic crisis. ${ }^{22}$

Because financial difficulties are often linked to losing one's job or being unemployed, it is clear that those who lose jobs are also vulnerable to the adverse effects of the economic crisis. ${ }^{40}$ Edwards found, more generally, in a longitudinal mortality study in the United States during the 1980s and the 1990s, that of those losing their jobs, the least well-educated workers are at greatest risk for ill health when jobs are lost during times of economic hardship. ${ }^{71}$

People with ill health also are at increased risk. A study in 27 European countries found that people with mental health problems not caused by the economic crisis are at greater risk of losing their job during economic crisis, especially men and individuals with lower levels of education. ${ }^{72}$ In Greece, those with mental illness and people attending drug rehabilitation programs were found to be particularly vulnerable to the adverse effects of the economic crisis. ${ }^{73}$

In Spain, Robert et al reported an increase in poor mental health among immigrant workers who experienced deterioration in their employment conditions, probably influenced by the economic crisis. ${ }^{74}$

Lopez Bernal reported that men and those of working age may be at particular risk for suicide associated with the crisis in Spain. ${ }^{19}$

\section{Strategies to cope with the negative effects of recession Health services}

Budget cuts will affect psychiatric services adversely just when economic stressors are raising the levels of need and demand in affected populations. ${ }^{22}$ Kentikelenis says greater attention to health and health care access is needed to ensure the Greek crisis does not undermine the ultimate source of the country's wealth: its people. ${ }^{1}$ He also stresses this imbalance between reduced resources and increased demand: Spending on mental health decreased by $45 \%$, despite much greater need resulting from the crisis. ${ }^{73}$ Cooper's conclusion is in the same direction: Economic mental health care could best be achieved not by decimating services but by planning and deploying these services to meet the needs of defined area populations. ${ }^{22}$ 
This is still more the case for low-income and transitional societies, in which even small reductions in health service budgets may be very damaging. The example of Pakistan makes this clear, because it is hard to see how this country, with an average of one psychiatrist for every 640,000 people, could make efficiency savings in mental health. ${ }^{22}$

Jonas Gahr Støre, Minister of Health and Care Services from Norway, warned about the potential adverse effects of austerity measures: "We must ensure that cost-cutting measures in the health sector do not increase social inequalities in health. Our ability to see and give priority to the weakest people in society must be our guiding principle in difficult economic times, as well as in good."21

Gili et al argue in favor of expanding mental health services in primary care settings to at-risk groups, which may help cope with rising mental health disorders in areas affected by recession. ${ }^{27} \mathrm{~A}$ higher level of vigilance toward mental health problems is suggested by several researchers. Services should become particularly attentive to the mental health effects of the crisis and should emphasize early recognition of depression and suicidal thoughts, possibly with the aid of mental health telephone helplines, as well as on the prevention of depression..$^{43}$ In particular, the general practitioner is allotted an important role in the continuous and reinforced assessment of suicidal risk in times of recession. ${ }^{28}$

\section{Social protection policies}

Different policy responses to economic crises can result in different health outcomes on a population level. A cited example is the contrast between Spain, where rising unemployment in the 1970s and 1980s was accompanied by a corresponding increase in suicide risk, and Sweden, whose own banking crisis in the 1990s likewise threw many people out of work, but where the suicide rate actually declined in that period. This marked difference has been ascribed to the protective effect of the Swedish welfare state..$^{40}$ In addition, Finland has managed to mitigate increases in suicides after marked economic recessions. ${ }^{40}$

Austria, with a strong social safety net, had a slight decline in suicides despite an increase in unemployment of 0.6 percentage points between 2007 and 2009. ${ }^{37}$ Uutela, in a review, concludes that it seems that active labor market programs existing in some Organisation for Economic Co-operation and Development countries can prevent some adverse health effects of economic downturns, that enough services for those in need should be provided, and that advocacy for societal support measures is of great importance. ${ }^{66}$
Thus, it seems that the effects on health of the financial crisis are largely dependent on the fiscal austerity policy and social protection measures in a country: Karanikolos mentions that the interaction of fiscal austerity with economic shocks and weak social protection is what ultimately seems to escalate health and social crises in Europe. ${ }^{6}$ Iceland rejected austerity through a popular vote, and the financial crisis seems to have had few or no discernible effects on health in that country. ${ }^{6}$

This means that policy measures intended to combat the economic crisis can result in severe adverse effects regarding the well-being of the population. As Kentikelenis writes: "If the policies adopted had actually improved the economy, then the consequences for health might be a price worth paying. However, the deep cuts have actually had negative economic effects, as acknowledged by the International Monetary Fund. Gross domestic product fell sharply and unemployment skyrocketed as a result of the economic austerity measures, which posed additional health risks to the population through deterioration of socioeconomic factors." ${ }^{\text {75 }}$

Interventions to combat economic exclusion and to promote social participation of individuals with mental health problems are even considered as more important during times of economic crisis. ${ }^{72}$ Bartoll et al agree with this statement: "Social protection policies need to be reinforced, especially among individuals from a disadvantaged socioeconomic position." ${ }^{45}$ They observed that the relative index of inequality by social class increased for men (an increase in the prevalence of poor mental health) in Spain between 2006-2007 and 2011-2012. ${ }^{45}$

Which measures should not and should be taken, then, during economic crises? The WHO lists resources in five key areas of social policy considered to be important: active labor market programs, family support programs, regulation of alcohol prices and availability, community health care for high-risk groups, and debt relief programs. ${ }^{76}$

Thus, it seems that governments might be able to protect their populations specifically by budgeting for measures that keep people employed, helping those who lose their jobs cope with the negative effects of unemployment, and enabling unemployed people to regain work quickly. ${ }^{40}$ The effect of positive policy measures can even be calculated: Stuckler et al found that every US\$10 per person increased investment in active labor market programs reduced the effect of unemployment on suicides by $0.038 \%{ }^{40}$ In addition, Baumbach et al found that the effect of unemployment on suicide is higher in countries with lower social spending, ${ }^{23}$ and Sir Michael Marmot 
said countries that had the greatest social spending had the lowest mortality rates. ${ }^{77}$

Rise in unemployment did not increase suicide risk in areas where annual spending on welfare programs was above US\$190 a head. Each additional US\$100 per person spent annually on active labor market programs reduced the effect on suicide rate by 0.4 percentage points, whereas each US $\$ 100$ per person spent on family support reduced the corresponding effect by 0.2 percentage points. ${ }^{40}$

Kentikelenis and Papanicolas give some concrete suggestions for policy measures to alleviate the adverse consequences of the recession in Greece; including, among others, a need to safeguard programs for vulnerable groups, such as those with mental illness and drug rehabilitation programs; increasing the number of general practitioners who work in rural areas; addressing the widespread out-ofpocket payments in primary care; and increasing generic prescribing to allow savings on drug expenditure to be reallocated to other important areas, such as recruitment of nursing staff. ${ }^{73}$

\section{Moderating and mediating mechanisms}

The negative effect of the economic crisis on mental health can sometimes be alleviated by the creativity and flexibility of people. Some mechanisms that can moderate the magnitude of the negative health consequences are, for instance, financial and psychological coping strategies and acculturation. Regarding financial coping, Dore et al give the example of low-income Russian families that adopt effective behavioral strategies to maintain dietary stability in times of economic crisis, such as purchasing less expensive foods or increasing the percentage of food that was home prepared. ${ }^{78}$ In addition, psychological coping strategies can be of importance. On the basis of panel data from Russia, Graham et al noted that happiness not only affects income but also health: people who were happier were in better health. ${ }^{79}$ In contrast, psychological factors may also mediate the increase in, for instance, all-cause or cause-specific mortality observed in association with economic crisis. ${ }^{80}$ Increased levels of stress or depression are found to be important indirect causes of the excess mortality observed during periods of economic crisis. ${ }^{81}$ Liem et al studied acculturation and emotion among Asian-Americans. It is clear that emotional life may undergo significant change during the acculturation process and that the ease of interpersonal interactions, for example, may be compromised when difficult-to-articulate, affectmediated reactions to similar situations by cultural natives and newcomers lead to miscommunication or conflict. ${ }^{82}$ Culturally mediated emotional meanings associated with life encounters are not easily recognized or articulated and, hence, may be especially problematic sources of distress when they conflict in interpersonal contexts. ${ }^{82}$ An interactive acculturation model that incorporates the acculturation orientations adopted by immigrant groups in the host community, acculturation orientations adopted by the host community group toward specific groups of immigrants, and interpersonal and intergroup relational outcomes that are the product of combinations of immigrant and host community acculturation orientations ${ }^{83}$ could help in coping with acculturation problems and act as a moderating mechanism in times of economic recession.

\section{Conclusion and future directions}

Although all-cause mortality rates do not show an increase during economic crises, and traffic accident mortality even shows a decrease, solid evidence shows almost incontrovertibly the existence of a relationship between the recent economic crisis and a rise in mental health problems resulting in suicides. ${ }^{84}$ This in spite of the fact that some researchers say it is still too early to speak about such a relationship.

The main reactions of most policy makers to the economic crisis are (severe) austerity measures. These measures seem to have, however, a detrimental effect on the mental health of the population, which is often deteriorated because of job loss resulting from the economic crisis: Just when people have the highest need for mental help, cost-cutting measures in the health care sector lead to a (substantial) drop in the supply of services for prevention, early detection, and cure of mental health problems. Especially vulnerable groups, such as people facing financial difficulties and people with ill health, are at increased risk. Moreover, the possibilities for policy makers to support moderating mechanisms such as financial and psychological coping and acculturation are until thus far underexploited. In addition, the role of primary health care workers in screening people at risk for suicidal thoughts, suicide attempts, and suicides, especially during economic crises, is not fully made use of yet. Several examples show that the countries best off regarding the mental health of their populations during the economic crisis are those countries with the strongest social safety net. Therefore, instead of cutting back on health care and social welfare measures, policy makers should in the future invest even more in social protection measures during economic crises. 


\section{Disclosure}

The author reports no conflicts of interest in this work.

\section{References}

1. Kentikelenis A, Karanikolos M, Papanicolas I, Basu S, McKee M, Stuckler D. Health effects of financial crisis: omens of a Greek tragedy. Lancet. 2011;378(9801):1457-1458.

2. Kentikelenis A, Karanikolos M, Papanicolas I, Basu S, McKee M, Stuckler D. Health and the financial crisis in Greece - Author's reply. Lancet. 2012;379(9820):1002.

3. Economou M, Madianos M, Theleritis C, Peppou LE, Stefanis CN. Increased suicidality amid economic crisis in Greece. Lancet. 2011; 378(9801): 1459

4. Economou M, Madianos M, Peppou LE, Theleritis C, Stefanis CN. Suicidality and the economic crisis in Greece. Lancet. 2012; 380(9839):337.

5. Polyzos N. Health and the financial crisis in Greece. Lancet. 2012; 379(9820): 1000

6. Karanikolos M, Mladovsky P, Cylus J, et al. Financial crisis, austerity, and health in Europe. Lancet. 2013;381(9874):1323-1331.

7. Gunnell D, Harbord R, Singleton N, Jenkins R, Lewis G. Factors influencing the development and amelioration of suicidal thoughts in the general population. Cohort study. Br J Psychiatry. 2004;185(5):385-393.

8. Goldney RD, Wilson D, Dal Grande E, Fisher LJ, McFarlane AC. Suicidal ideation in a random community sample: attributable risk due to depression and psychosocial and traumatic events. Aust $N Z J$ Psychiatry. 2000;34(1):98-106.

9. Hintikka J, Pesonen T, Saarinen P, Tanskanen A, Lehtonen J, Viinamaki H. Suicidal ideation in the Finnish general population. A 12-month follow-up study. Soc Psychiatry Psychiatr Epidemiol. 2001;36(12):590-594.

10. Kjøller M, Helweg-Larsen M. Suicidal ideation and suicide attempts among adult Danes. Scand J Public Health. 2000;28(1):54-61.

11. Paykel ES, Myers JK, Lindenthal JJ, Tanner J. Suicidal feelings in the general population: a prevalence study. Br J Psychiatry. 1974;124(0): 460-469.

12. Thomas HV, Crawford M, Meltzer H, Lewis G. Thinking life is not worth living. A population survey of Great Britain. Soc Psychiatry Psychiatr Epidemiol. 2002;37(8):351-356.

13. Weissman MM, Bland RC, Canino GJ, et al. Prevalence of suicide ideation and suicide attempts in nine countries. Psychol Med. 1999;29(1): 9-17.

14. Fountoulakis KN, Grammatikopoulos IA, Koupidis SA, Siamouli M, Theodorakis PN. Health and the financial crisis in Greece. Lancet. 2012;379(9820):1001-1002.

15. Fountoulakis KN, Siamouli M, Grammatikopoulos IA, Koupidis SA, Siapera M, Theodorakis PN. Economic crisis-related increased suicidality in Greece and Italy: a premature overinterpretation. $J$ Epidemiol Community Health. 2013;67(4):379-380.

16. Liaropoulos L. Greek economic crisis: not a tragedy for health. $B M J$. 2012;345:e7988.

17. Kentikelenis A, Karanikolos M, Papanicolas I, Basu S, McKee M, Stuckler D. Effects of Greek economic crisis on health are real. $B M J$. 2012;345:e8602.

18. Librero J, Segura A, Beatriz LV. Suicides, hurricanes and economic crisis. Eur J Public Health. 2014;24(2):183.

19. Lopez Bernal J, Gasparrini A, Artundo C, McKee M. RE: The effect of the late 2000s financial crisis on suicides in Spain: an interrupted time-series analysis. Eur J Public Health. 2014;24(2):183-184.

20. McKimmie M. Health cuts have consequences: expert. Perth: The West Australian. Available from: http://health.thewest.com.au/news/1499/ health-cuts-have-consequences-expert. Accessed July 22, 2014.

21. World Health Organization. Oslo conference on health systems and the economic crisis. Geneva: World Health Organization. Available from: http://www.euro.who.int/en/media-centre/events/events/2013/04/ oslo-conference-on-health-systems-and-the-economic-crisis. Accessed July 23, 2014.
22. Cooper B. Economic recession and mental health: an overview. Neuropsychiatr. 2011;25(3):113-117.

23. Baumbach A, Gulis G. Impact of financial crisis on selected health outcomes in Europe. Eur J Public Health. 2014;24(3):399-403.

24. Chang SS, Stuckler D, Yip P, Gunnell D. Impact of 2008 global economic crisis on suicide: time trend study in 54 countries. BMJ. 2013;347:f5239.

25. Schmidtke A, Bille-Brahe U, DeLeo D, et al. Attempted suicide in Europe: rates, trends and sociodemographic characteristics of suicide attempters during the period 1989-1992. Results of the WHO/EURO Multicentre Study on Parasuicide. Acta Psychiatr Scand. 1996;93(5):327-338.

26. Borges G, Nock MK, Haro Abad JM, et al. Twelve-month prevalence of and risk factors for suicide attempts in the World Health Organization World Mental Health Surveys. J Clin Psychiatry. 2010;71(12): $1617-1628$.

27. Gili M, Roca M, Basu S, McKee M, Stuckler D. The mental health risks of economic crisis in Spain: evidence from primary care centres, 2006 and 2010. Eur J Public Health. 2013;23(1):103-108.

28. Vanderoost F, van der Wielen S, van Nunen K, Van Hal G. Employment loss during economic crisis and suicidal thoughts in Belgium: a survey in general practice. Br J Gen Pract. 2013;63(615):e691-e697.

29. Rihmer Z, Kapitany B, Gonda X, Dome P. Suicide, recession, and unemployment. Lancet. 2013;381(9868):722-723.

30. Reeves A, Stuckler D, McKee M, Gunnell D, Chang SS, Basu S. Increase in state suicide rates in the USA during economic recession. Lancet. 2012;380(9856):1813-1814.

31. Robert G, Martinez JM, Garcia AM, Benavides FG, Ronda E. From the boom to the crisis: changes in employment conditions of immigrants in Spain and their effects on mental health. Eur J Public Health. 2014;24(3):404-409.

32. Loverdos A. Response to Question by Member of Parliament, Reference Number: 56885. Athens: Ministry of Health and Social Solidarity; 2011.

33. Katsadoros D, Bekiari E, Karydi K, et al. Suicide help line 1018: characteristics of callers for January-December 2010. Presented at: 21st Panhellenic Conference of Psychiatry; May 5-7; 2011; Athens, Greece.

34. Tsimas P. Erevna. Greece: Mega TV; 2011.

35. Lopez Bernal JA, Gasparrini A, Artundo CM, McKee M. The effect of the late 2000s financial crisis on suicides in Spain: an interrupted time-series analysis. Eur J Public Health. 2013;23(5):732-736.

36. De Vogli R, Marmot M, Stuckler D. Excess suicides and attempted suicides in Italy attributable to the great recession. J Epidemiol Community Health. 2013;67(4):378-379.

37. Stuckler D, Basu S, Suhrcke M, Coutts A, McKee M. Effects of the 2008 recession on health: a first look at European data. Lancet. 2011; 378(9786):124-125.

38. Ryall J. Japanese suicides rise as world recession hits country's businessmen. London: The Telegraph; 2009. Available from: http:// www.telegraph.co.uk/news/worldnews/asia/japan/5273786/Japanesesuicides-rise-as-world-recession-hits-countrys-businessmen.html. Accessed July 18, 2014

39. Chang SS, Gunnell D, Sterne JA, Lu TH, Cheng AT. Was the economic crisis 1997-1998 responsible for rising suicide rates in East/Southeast Asia? A time-trend analysis for Japan, Hong Kong, South Korea, Taiwan, Singapore and Thailand. Soc Sci Med. 2009;68(7):1322-1331.

40. Stuckler D, Basu S, Suhrcke M, Coutts A, McKee M. The public health effect of economic crises and alternative policy responses in Europe: an empirical analysis. Lancet. 2009;374(9686):315-323.

41. De Vogli R, Vieno A, Lenzi M. Mortality due to mental and behavioral disorders associated with the Great Recession (2008-2010) in Italy: a time trend analysis. Eur J Public Health. 2014;24(3):419-421.

42. Platt S, Hawton K. Suicidal behaviour and the labour market. In: Hawton $\mathrm{K}$, van Heeringen $\mathrm{K}$, editors. International Handbook of Suicide and Attempted Suicide. Chichester: John Wiley; 2000:309-384.

43. Economou M, Madianos M, Peppou LE, Patelakis A, Stefanis CN. Major depression in the era of economic crisis: a replication of a crosssectional study across Greece. J Affect Disord. 2013;145(3):308-314. 
44. Roca M, Gili M, Garcia-Campayo J, Garcia-Toro M. Economic crisis and mental health in Spain. Lancet. 2013;382(9909):1977-1978.

45. Bartoll X, Palencia L, Malmusi D, Suhrcke M, Borrell C. The evolution of mental health in Spain during the economic crisis. Eur J Public Health. 2014;24(3):415-418.

46. Men T, Brennan P, Boffetta P, Zaridze D. Russian mortality trends for 1991-2001: analysis by cause and region. BMJ. 2003;327(7421):964.

47. Shkolnikov V, McKee M, Leon DA. Changes in life expectancy in Russia in the mid-1990s. Lancet. 2001;357(9260):917-921.

48. Gavrilova NS, Semyonova VG, Evdokushkina GN, Gavrilov LA. The response of violent mortality to economic crisis in Russia. Popul Res Policy Rev. 2000;19(5):397-419.

49. Notzon FC, Komarov YM, Ermakov SP, Sempos CT, Marks JS, Sempos EV. Causes of declining life expectancy in Russia. JAMA. 1998;279(10):793-800.

50. Leon DA, Chenet L, Shkolnikov VM, et al. Huge variation in Russian mortality rates 1984-94: artefact, alcohol, or what? Lancet. 1997;350(9075):383-388.

51. Hellastat. Sector Study: Alcoholic Beverages. Athens. Hellastat; 2010.

52. EKTEPN. Annual Report on the State of the Drugs and Alcohol Problem. Athens: Greek Documentation and Monitoring Centre for Drugs; 2010

53. Harhay MO, Bor J, Basu S, et al. Differential impact of the economic recession on alcohol use among white British adults, 2004-2010. Eur J Public Health. 2014;24(3):410-415.

54. Telloglou T. Interview with Minister of Health Andreas Loverdos. In: Papahelas A, Telloglou T, Papaioannou S, editors. Folders. Greece: Skai TV; 2011.

55. Telloglou T, Kakaounaki M. Three weeks, one night on duty. In: Papahelas A, Telloglou T, Papaioannou S, editors. Folders. Greece: Skai TV; 2011.

56. Liakopoulou T. Since last year private hospitals are in trouble while NHS is doing better. Kathimerini. June 12, 2011.

57. Hellastat. Sector Study: Health Services. Athens: Hellastat; 2010.

58. Karatziou D. Society in humanitarian crisis. Kyriakatiki Eleftherotypia. July 24, 2011.

59. Paraskevis D, Hatzakis A. An ongoing HIV outbreak among intravenous drug users in Greece: preliminary summary of surveillance and molecular epidemiology data. EMCDDA Early Warning System; 2011.

60. EKTEPN. Report of the ad hoc expert group of the Greek focal point on the outbreak of HIV/AIDS in 2011. Athens: Greek Documentation and Monitoring Centre for Drugs; 2011.

61. Carassava A. Crime casts long shadow over Athens. Los Angeles, Los Angeles Times; May 31, 2011. Available from: http://articles.latimes. com/2011/may/31/world/la-fg-greece-austerity-20110531. Accessed July 23, 2014.

62. Krug EG, Mercy JA, Dahlberg LL, Zwi AB. The world report on violence and health. Lancet. 2002;360(9339):1083-1088.

63. Sundquist K, Theobald H, Yang M, Li X, Johansson SE, Sundquist J. Neighborhood violent crime and unemployment increase the risk of coronary heart disease: a multilevel study in an urban setting. Soc Sci Med. 2006;62(8):2061-2071.

64. Abbott P, Wallace C. Explaining economic and social transformation in Post-Soviet Russia, Ukraine and Belarus. Eur Soc. 2010;12(5): 653-674.
65. Thomas S, Burke S, Barry S. The Irish health-care system and austerity: sharing the pain. Lancet. 2014;383(9928):1545-1546.

66. Uutela A. Economic crisis and mental health. Curr Opin Psychiatry. 2010;23(2):127-130.

67. Fountoulakis KN, Koupidis SA, Siamouli M, Grammatikopoulos IA, Theodorakis PN. Suicide, recession, and unemployment. Lancet. 2013;381(9868):721-722.

68. Perlman F, Bobak M. Assessing the contribution of unstable employment to mortality in posttransition Russia: prospective individual-level analyses from the Russian longitudinal monitoring survey. Am J Public Health. 2009;99(10):1818-1825.

69. Reeves A, Stuckler D, McKee M, Gunnell D, Chang SS, Basu S. Suicide, recession, and unemployment - authors' reply. Lancet. 2013;381(9868):722.

70. Jenkins R, Bhugra D, Bebbington P, et al. Debt, income and mental disorder in the general population. Psychol Med. 2008;38(10):1485-1493.

71. Edwards R. Who is hurt by procyclical mortality? Soc Sci Med. 2008;67(12):2051-2058.

72. Evans-Lacko S, Knapp M, McCrone P, Thornicroft G, Mojtabai R. The mental health consequences of the recession: economic hardship and employment of people with mental health problems in 27 European countries. PLoS ONE. 2013;8(7):e69792.

73. Kentikelenis A, Papanicolas I. Economic crisis, austerity and the Greek public health system. Eur J Public Health. 2012;22(1):4-5.

74. Robert G, Martinez JM, GarciaAM, Benavides FG, Ronda E. From the boom to the crisis: changes in employment conditions of immigrants in Spain and their effects on mental health. Eur J Public Health. 2014;24(3):404 409.

75. Kentikelenis A, Karanikolos M, Reeves A, McKee M, Stuckler D. Greece's health crisis: from austerity to denialism. Lancet. 2014; 383(9918):748-753.

76. World Health Organization. Impact of Economic Crises on Mental Health. Copenhagen: World Health Organization; 2011. Available from: http://www.euro.who.int/_data/assets/pdf_file/0008/134999/e94837. pdf. Accessed July 20, 2014.

77. Limb M. Austerity measures will lead to rise in unemployment and suicides, says Marmot. BMJ. 2012;344:e2887.

78. Dore AR, Adair LS, Popkin BM. Low income Russian families adopt effective behavioral strategies to maintain dietary stability in times of economic crisis. J Nutr. 2003;133(11):3469-3475.

79. Graham C, Eggers A, Sukhtankar S. Does happiness pay? An exploration based on panel data from Russia. J Econ Behav Organ. 2004;55:319-342.

80. Falagas ME, Vouloumanou EK, Mavros MN, Karageorgopoulos DE. Economic crises and mortality: a review of the literature. Int J Clin Pract. 2009;63(8):1128-1135.

81. Colledge M. Economic cycles and health. Towards a sociological understanding of the impact of the recession on health and illness. Soc Sci Med. 1982;16(22):1919-1927.

82. Liem R, Lim BA, Liem JH. Acculturation and emotion among Asian Americans. Cultur Divers Ethnic Minor Psychol. 2000;6(1):13-31.

83. Bourhis RY, Moise LC, Perreault S, Senecal S. Towards an interactive acculturation model: a social psychological approach. Int J Psychol. 1997;32(6):369-386.

84. De Vogli R, Marmot M, Stuckler D. Strong evidence that the economic crisis caused a rise in suicides in Europe: the need for social protection. [Commentary]. J Epidemiol Community Health. 2013;67(4):298.

Psychology Research and Behavior Management

\section{Publish your work in this journal}

Psychology Research and Behavior Management is an international, peerreviewed, open access journal focusing on the science of psychology and its application in behavior management to develop improved outcomes in the clinical, educational, sports and business arenas. Specific topics covered include: Neuroscience, memory \& decision making; Behavior

modification \& management; Clinical applications; Business \& sports performance management; Social and developmental studies; Animal studies. The manuscript management system is completely online and includes a quick and fair peer-review system. Visit http://www.dovepress. com/testimonials.php to read real quotes from published authors. 